\title{
Mutantes morfológicos de algodoeiro herbáceo como fonte de resistência ao bicudo
}

\author{
Francisco das Chagas Vidal Neto ${ }^{(1)}$, Fanuel Pereira da Silva(2), Ervino Bleicher ${ }^{(2)}$ \\ e Francisco Ivaldo Oliveira Melo(2)
}

(1)Embrapa Algodão, Caixa Postal 174, CEP 58107-720 Campina Grande, PB. E-mail: vidal@cnpa.embrapa.br (2)Universidade Federal do
Ceará, Dep. de Fitotecnia, Campus do Pici, Bloco 805, CEP 60451-970 Fortaleza, CE. E-mail: fanuel@ufc.br, ervino@ufc.br, ivaldo@ufc.br

Resumo - Este trabalho teve como objetivo avaliar os efeitos de três características morfológicas mutantes de linhagens de algodoeiro herbáceo (Gossypium hirsutum L. r. latifolium Hutch.), isoladas ou combinadas no mesmo genótipo, como fonte de resistência ao bicudo, Anthonomus grandis Boheman, 1843 (Coleoptera, Curculionidae). O experimento foi conduzido em campo, sob infestação natural, com delineamento de blocos ao acaso e arranjo fatorial $2 \times 3 \mathrm{com}$ um tratamento adicional, com quatro repetições. Em teste com chance de escolha, a característica bráctea frego foi a que apresentou maior redução no dano de oviposição pelo bicudo $(34,71 \%)$, em relação ao equivalente normal. A folha "okra" reduziu o dano apenas quando associada à bráctea frego (40\%). A combinação das três características mutantes na mesma planta proporcionou a menor porcentagem de botões com dano de oviposição $(23,13 \%)$.

Termos para indexação: Gossypium hirsutum, Anthonomus grandis, isolinhas, folha okra, bráctea frego.

\section{Morphological mutants of upland cotton as source of boll weevil resistance}

\begin{abstract}
This work aimed to evaluate the effects of three morphological mutants of upland cotton lines (Gossypium hirsutm L. r. latifolium Hutch.), isolated or in combination in the same cotton genotype, as a source of resistance to boll weevil, Anthonomus grandis Boheman, 1843 (Coleoptera, Curculionidae). The experiment was carried out in the field, under natural infestation, with a completely randomized block design arranged in a factorial $2 \times 3$ plus an additional treatment, with four replications. In a multiple choice test, the character mutant frego bract presented the higher reduction on boll weevil oviposition damage (34.71\%), in relation to the normal equivalent. The okra leaf reduced the boll weevil damage only when associated with frego bract (40\%). The combination of the three mutant characters in the same plant presented the least square percent with oviposition damage $(23.13 \%)$.
\end{abstract}

Index terms: Gossypium hirsutum, Anthonomus grandis, isolines, okra leaf, frego bract.

\section{Introdução}

A busca por cultivares de algodoeiro resistentes às pragas começou no início do século XX, com as primeiras descobertas de características morfológicas mutantes. Os estudos genéticos realizados com os caracteres folha "okra", bráctea frego e planta vermelha mostraram que eram herdados monogeneticamente e podiam ser facilmente manipulados e introduzidos em novas bases genéticas, para estudos de resistência (Cateland \& Schwendiman, 1976; Jones et al., 1986).

$\mathrm{O}$ caráter planta vermelha $\left(\mathrm{R}_{1}\right)$, de dominância incompleta, foi o primeiro a ser reconhecido como um fator de resistência ao bicudo, baseado no mecanismo de não-preferência para alimentação (Maxwell, 1977; Weaver Junior \& Reddy, 1977; Soares et al., 1999).

A bráctea frego é controlada por um único loco recessivo (fg) e considerada por muitos autores como o caráter mais promissor para o emprego comercial em cultivares resistentes ao bicudo. Está associada a um alto nível de resistência, que pode reduzir em $50 \%$ os danos aos botões florais e em $46 \%$ o uso de inseticidas para o controle da praga (Jenkins \& Parrott, 1971; Jones, 1972). O seu efeito em relação à praga foi atribuído à inibição da alimentação e da oviposição, além da eliminação de abrigo contra os inseticidas e os inimigos naturais, aumentando a eficiência do parasitismo aos ovos e às larvas (Hunter et al., 1965). Nestas condições as fê- 
meas tornam-se inquietas, com maior movimentação entre plantas, precisando do dobro do tempo para realizar as picadas de alimentação e postura, ovipositando a metade dos ovos, em relação à bráctea normal e ficando sujeitas a uma maior contaminação por inseticidas (Mitchell et al., 1973; Parrott, et al., 1973). Parrott et al. (1973) constataram que, nos botões florais com bráctea frego, foi recuperado sete vezes mais inseticida que nos normais, aumentando a eficiência das formulações concentrado emulsionável e propiciando o uso de ultra-baixo volume de azinfosethil, no controle do bicudo.

O mutante folha "okra" $\left(\mathrm{L}_{2}^{\circ}\right)$ apresenta dominância incompleta em relação à folha normal $\left(1^{\circ}\right)$ e caracterizase por folhas profundamente recortadas. Essa característica proporciona uma condição ecológica adversa ao bicudo, permitindo maior penetração dos raios solares, o que reduz a umidade relativa no ambiente da planta, aumentando a mortalidade das formas imaturas. Além disso, permite maior penetração dos inseticidas, aumentando sua eficiência sobre o inseto adulto (Maxwell, 1977; Jones et al., 1986; Vassayre et al., 1996).

Para muitos autores, a combinação de caracteres de resistência a pragas em uma cultivar poderá viabilizar o uso de cultivares resistentes em um programa de manejo integrado de pragas (MIP), viabilizando o seu emprego comercial (Weaver Junior \& Reddy, 1977; Jones et al., 1986; Soares, 1992; Vieira \& Lima, 1999). Este método já vem sendo empregado com sucesso na Austrália, nas variedades "Siokra", por meio da combinação bráctea frego, ausência de pelos e de nectários, e foi introduzida no mercado comercial americano (Llewellyn et al., 1992; Monks et al., 1999). Resultados animadores foram obtidos, tanto pelo emprego exclusivo dos métodos convencionais, como pela intermediação da biotecnologia ou pela associação de ambos (Sachs et al., 1993, 1996; Smith, 1997; Thaxton \& El-Zik, 1997, 2000).

O objetivo deste trabalho foi avaliar os efeitos de três características morfológicas de linhagens de algodoeiro herbáceo, isoladas ou associadas em um mesmo genótipo, como fontes de resistência ao bicudo.

\section{Material e Métodos}

O material genético utilizado constou de oito linhagens quase isogênicas, em uma base genética REBA, e uma cultivar testemunha, BRS 187 8H, desenvolvida pela Embrapa Algodão, para as condições do Nordeste do
Brasil. As isolinhas testadas incluíram todas as oito combinações homozigotas possíveis dos caracteres mutantes folha "okra", bráctea frego e planta vermelha, com as equivalentes normais, obtidas em projeto de pesquisa conduzido na Universidade Federal do Ceará (UFC).

O experimento para avaliação da resistência ao bicudodo-algodoeiro foi conduzido em campo, sob irrigação por aspersão e infestação natural, na Fazenda Experimental do Vale do Curu, localizada em Pentecoste, CE, pertencente à UFC, em 2000.

Empregou-se o delineamento experimental de blocos ao acaso, com quatro repetições, em fatorial $2 \times 3$, com um tratamento adicional, em que os fatores eram representados pelas características morfológicas para forma da folha, tipo de bráctea e cor da planta e os níveis, pelos estados mutante e normal. $\mathrm{O}$ tratamento adicional foi representado pela testemunha, a cultivar BRS $1878 \mathrm{H}$. As parcelas constaram de quatro fileiras de $6 \mathrm{~m}$ de comprimento, espaçadas em $0,80 \mathrm{~m}$, com 5 plantas por metro linear de fileira e área útil correspondendo às duas fileiras centrais. A adubação foi realizada com NPK (60-60-30) e as práticas culturais seguiram as recomendações para a cultura. Não foi realizado qualquer controle de pragas após o aparecimento dos botões florais. Aos 22 dias após a emergência das plantas, foi realizada uma pulverização contra o pulgão (Aphis gossypii Glover, 1876), utilizando-se $0,5 \mathrm{~L} \mathrm{ha}^{-1}\left(0,2 \mathrm{~kg} \mathrm{ha}^{-1}\right.$ do i.a. $)$ do produto comercial Agritoato $400 \mathrm{CE}$ (Dimetoato).

As avaliações para a determinação da resistência constaram do exame de dez botões florais preferidos pelo bicudo $(\phi \geq 6 \mathrm{~mm})$, coletados ao acaso, na área útil das parcelas (5 plantas/fileira), para a identificação de orifícios de oviposição. As plantas com mais que um orifício eram consideradas atacadas e os dados registrados com base no porcentual de ataque. Durante o ciclo da cultura foram realizados oito levantamentos semanais, iniciando-se a partir da ocorrência dos primeiros botões florais preferidos.

A análise de variância conjunta dos dados foi realizada segundo o delineamento de blocos ao acaso, com parcelas subdivididas e quatro repetições. As parcelas constaram das características morfológicas estudadas e suas combinações, além de uma testemunha adicional, representada pela variedade comercial BRS 187 8H. As subparcelas constaram dos levantamentos realizados. Foi realizada a análise de regressão da porcentagem de oviposição em função dos levantamentos, em todas as características morfológicas estudadas. 


\section{Resultados e Discussão}

A oviposição do bicudo, que segundo Jenkins \& Parrot (1971) é uma determinação indireta da população, foi intensa já nas primeiras avaliações e está relacionada com a população de hibernação, que no caso era alta, tendo em vista que o ensaio foi plantado próximo a uma soqueira de algodão do ano anterior.

A análise conjunta dos oito levantamentos realizados apresentou diferenças altamente significativas entre os tratamentos, indicando respostas diferenciadas em relação à oviposição do bicudo (Tabela 1).

Os efeitos da forma da folha, da cor da planta ou da forma da bráctea, foram altamente significativos, favorecendo aos caracteres mutantes (folha "okra", bráctea frego e planta vermelha), em relação aos correspondentes normais. Isto demonstra a menor preferência do bicudo pelos tipos mutantes. A testemunha e a linhagem normal para as características estudadas apresentaram os mais altos níveis de oviposição.

A interação tripla significativa apontou para a existência de influência mútua entre os três fatores na resposta à preferência para oviposição pelo bicudo. A forma da folha teve efeito significativo apenas quando associada com a bráctea frego, independentemente da cor da planta (Figura 1). O caráter folha "okra", sozinho, não foi capaz de reduzir a oviposição. Seu efeito se dá de modo indireto, por meio do favorecimento da morte de larvas presentes em botões florais caídos, em solos com altas temperaturas (Maxwell, 1977). Nestas condições, a associação com a bráctea frego apresentou efeito aditivo sobre a redução da oviposição do bicudo, que foi mais acentuada na presença da planta vermelha. A associação das três características mutantes resultou numa taxa média de oviposição de $23,13 \%$.

O caráter bráctea frego reduziu significativamente a oviposição do bicudo em todas as associações envolvendo essa característica, independentemente da forma da folha e cor da planta serem mutantes ou normais (Figura 1), corroborando os resultados de Jenkins \& Parrot (1971) e Weaver Junior \& Reddy (1977), que sugerem um possível efeito antibiótico. Este efeito supressivo foi mais acentuado na presença da folha "okra" e da planta vermelha, em relação aos tipos normais (Figura 1).

$\mathrm{O}$ alto grau de resistência associado à bráctea frego pode ser explicado pelas mudanças provocadas no comportamento do inseto, em relação à bráctea normal. Segundo Mithchel (1973), a maior movimentação das fêmeas nas plantas com bráctea frego retarda as pica-

Tabela 1. Análise de variância conjunta de oito levantamentos de ataque do bicudo-do-algodoeiro, realizados durante o ciclo da cultura, considerando-se os caracteres morfológicos estudados ${ }^{(1)}$.

\begin{tabular}{|c|c|c|c|c|}
\hline Fonte de variação & GL & SQ & QM & $\mathrm{F}$ \\
\hline Bloco & 3 & $1.178,82$ & - & - \\
\hline Tratamento & (8) & $140.759,03$ & $17.594,88$ & $181,67^{* *}$ \\
\hline Testemunha $\times$ demais & 1 & $22.437,54$ & $22.437,54$ & $231,67^{* *}$ \\
\hline Forma $(\mathrm{A})$ & 1 & $3.984,77$ & $3.984,77$ & $41,14^{* *}$ \\
\hline Bráctea (B) & 1 & $76.659,77$ & $76.659,77$ & $791,53^{* *}$ \\
\hline Cor da planta (D) & 1 & $30.406,64$ & $30.406,64$ & $313,96^{* *}$ \\
\hline$(\mathrm{A} \times \mathrm{B})$ & 1 & $3.675,39$ & $3.675,39$ & $37,95^{* *}$ \\
\hline$(\mathrm{A} \times \mathrm{D})$ & 1 & 656,64 & 656,64 & $6,78^{*}$ \\
\hline$(\mathrm{B} \times \mathrm{D})$ & 1 & 375,39 & 375,39 & $3,88^{\mathrm{ns}}$ \\
\hline$(A \times B \times D)$ & 1 & $2.562,89$ & $2.562,89$ & $26,46^{* *}$ \\
\hline Resíduo (a) & 24 & $2.324,31$ & 96,85 & - \\
\hline Levantamento & 7 & $36.649,65$ & $5.235,66$ & $63,75^{* *}$ \\
\hline Testemunha vs. levantamento vs. fatorial & 7 & $2.965,58$ & 423,65 & $5,16^{* *}$ \\
\hline$($ Levantamento $) \times(\mathrm{A})$ & 7 & $2.155,86$ & 307,98 & $3,75^{* *}$ \\
\hline$($ Levantamento $) \times(B)$ & 7 & $6.193,36$ & 884,77 & $10,77^{* *}$ \\
\hline$($ Levantamento $) \times(\mathrm{D})$ & 7 & $3.996,48$ & 570,93 & $6,95^{* *}$ \\
\hline$($ Levantamento $) \times(\mathrm{A} \times \mathrm{B})$ & 7 & 340,23 & 48,60 & $0,59^{\text {ns }}$ \\
\hline$($ Levantamento $) \times(\mathrm{A} \times \mathrm{D})$ & 7 & 608,98 & 87,00 & $1,06^{\mathrm{ns}}$ \\
\hline$($ Levantamento $) \times(B \times D)$ & 7 & $1.102,73$ & 157,53 & $1,92^{\mathrm{ns}}$ \\
\hline$($ Levantamento $) \times(A \times B \times D)$ & 7 & $1.127,73$ & 161,10 & $1,96^{\mathrm{ns}}$ \\
\hline Resíduo (b) & 189 & $15.521,88$ & 82,13 & - \\
\hline Total & 287 & $214.924,65$ & - & - \\
\hline
\end{tabular}

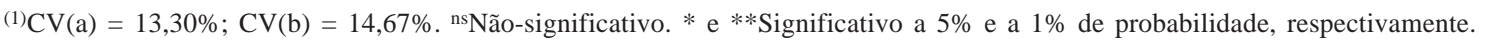


das de alimentação e postura, reduzindo o número de ovos colocados por unidade de tempo, além de dispersar os adultos por toda a planta, diminuindo a sua concentração nos botões florais.

O caráter planta vermelha reduziu significativamente a oviposição do bicudo em todas as associações envolvendo esta característica, independentemente da forma da folha e do tipo de bráctea serem mutantes ou normais (Figura 1). Isto significa a presença do efeito independente desta característica sobre a oviposição, embora menor do que o da bráctea frego, que, segundo Jones et al. (1986), se deve à percepção das cores pelo
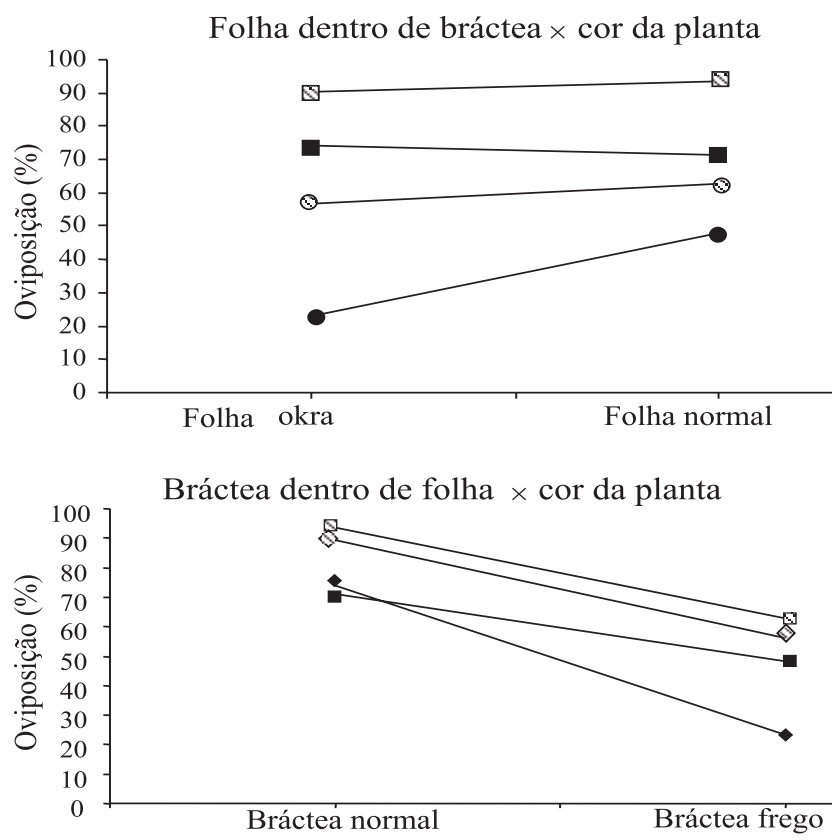

Cor da planta dentro de bráctea $\times$ folha

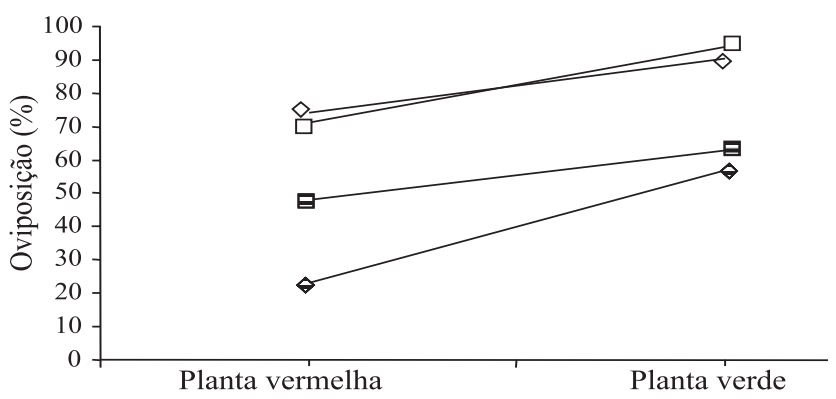

Figura 1. Interação forma da folha $\times$ tipo de bráctea $\times$ cor da planta, em relação à preferência do bicudo do algodoeiro para oviposição. Pontos representam características normal-ver-

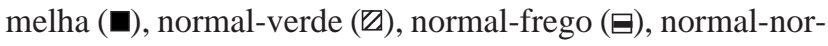
mal $(\square)$, frego-vermelha $(\bullet)$, frego-verde ( $\oslash)$, okra-vermelha $(\diamond)$, okra-verde $(\diamond)$, okra-frego $(\diamond)$ e okra-normal $(\diamond)$. inseto. O maior efeito foi observado na combinação com "okra"-frego, em que a presença da planta vermelha reduziu a oviposição do bicudo em $33,75 \%$.

A combinação de todas as características mutantes em uma planta proporcionou redução na preferência para oviposição em teste com chance de escolha. Vários autores, entre os quais Soares (1992), estudando fregovermelha, Hunter et al. (1965), com vermelha-pilosa, e Weaver Junior \& Reddy (1977), com frego-vermelhamacho-fértil, conseguiram aumentar a não-preferência do bicudo para oviposição por meio da associação desses caracteres morfológicos.

A fonte de variação 'levantamento' foi altamente significativa, evidenciando a diferença na oviposição do bicudo em relação à evolução do ciclo da cultura (Tabela 1). Esta variação pode ser observada pelos desdobramentos das interações levantamentos $\times$ efeitos principais (forma da folha, tipo de bráctea e cor da planta).

Observou-se crescimento diferenciado do dano do bicudo entre as características folha normal e folha "okra" (Figura 2). Estas características apresentaram porcentagens de oviposição semelhantes no início dos levantamentos, sugerindo que a forma da folha não teve efeito nesta fase. Após o segundo levantamento, verificou-se um aumento progressivo das diferenças entre os porcentuais de oviposição para as formas da folha até os levantamentos intermediários (6º), a partir dos quais estes voltaram a diminuir, com o aumento da população da praga no final do ciclo da cultura. As diferenças significativas entre as formas da folha ocorreram desde o 4ㅇá a $8^{\circ}$ levantamento.

O efeito negativo do clima quente e seco sobre populações de bicudo é bastante conhecido, mesmo em plantas com folhas normais, tornando-se mais importante em climas semi-áridos, onde as condições de alta temperatura e baixa umidade são mais frequientes. Mediante a modificação das condições ecológicas preferidas pelo bicudo, a característica folha "okra" exerce um efeito indireto, criando um microclima adverso, em virtude da redução da massa foliar da planta em até $40 \%$ e o conseqüente aumento de temperatura e umidade (Andries et al., 1969; Jones et al., 1986). Todavia, a diferenciação das folhas "okra" só começa após a 3 a folha verdadeira, a partir da qual a diferença em área foliar acentua-se, até alcançar o índice de área foliar máximo que, segundo Oosterhuis (1999), ocorre por volta dos 75 dias, por ocasião do fechamento da copa. Este comportamento coincide com a evolução da resposta 
relativa observada entre as linhagens com folha "okra" e seu equivalente normal, em relação à oviposição do bicudo. De acordo com este raciocínio, não era de se esperar que ocorresse diferença significativa em área foliar decorrente da forma da folha no início dos levantamentos, de modo a influenciar a preferência da praga para oviposição. O incremento na área foliar provoca uma alteração substancial no microclima da planta, aumentando seu efeito sobre o comportamento do inseto. Isto ocorre até que o aumento populacional da praga elimine a vantagem decorrente da copa aberta. $\mathrm{O}$ posicionamento dos primeiros botões florais no topo da planta também reduz a possibilidade do efeito diferencial de sombreamento e de proteção contra os inimigos naturais entre as linhagens com folha "okra" e aquelas com folha normal.
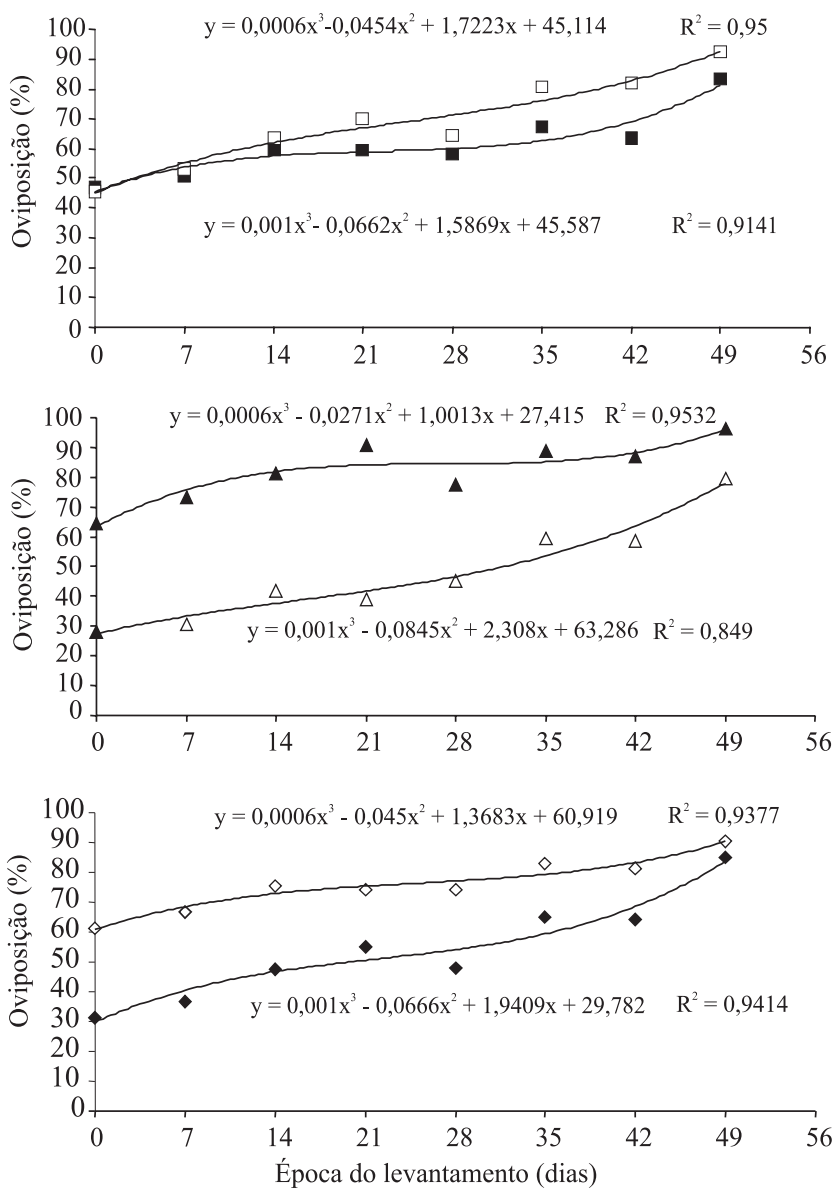

Figura 2. Comportamento das características folhas okra e normal $(\square)$; brácteas normal $(\boldsymbol{\Delta})$ e frego $(\triangle)$ e plantas vermelha $(\vec{\nabla})$ e verde $(\Delta)$, em oito levantamentos semanais realizados, em relação à preferência para oviposição do bicudodo-algodoeiro.
A porcentagem de oviposição foi significativamente menor para a característica bráctea frego, em relação ao correspondente normal, em todos os levantamentos realizados (Figura 2). A oviposição do bicudo foi 35\% menor nas linhagens com bráctea frego, no primeiro levantamento, em relação ao equivalente normal. Este comportamento mostra que o efeito da bráctea frego, ao contrário da folha "okra", manifesta-se logo no início da infestação do inseto. Esta diferença de resposta foi diminuindo à medida que a população da praga foi aumentando. Hunter et al. (1965) também verificaram que a bráctea frego inibiu a postura e a alimentação do bicudo, até que a pressão populacional se tornasse muito alta.

O caráter planta vermelha proporcionou reduções significativas na porcentagem de oviposição do bicudo, em relação ao equivalente planta verde, em quase todos os levantamentos realizados, exceto no último ( 8 o). A exemplo do tipo de bráctea, a diferença na porcentagem de oviposição foi inicialmente alta, reduzindo-se à medida que houve aumento da população da praga (Figura 2). No primeiro levantamento, a planta vermelha proporcionou uma redução de $31,14 \%$ na oviposição, de acordo com as equações de regressão. Estes resultados comprovam que a menor preferência do bicudo pelos tipos mutantes para bráctea e cor da planta manteve a oviposição da praga em cerca de $50 \%$, em relação aos correspondentes normais, até o 40 e e 20 levantamentos, respectivamente. Isto demonstra que a bráctea frego tem um efeito mais prolongado do que a planta vermelha. Este comportamento se assemelha ao verificado por Jenkins \& Parrott (1971) e Jones (1972).

Com base no padrão de comportamento observado (Figura 2), pode-se inferir um possível efeito de complementaridade temporal das combinações folha "okra"-bráctea frego e folha "okra"-planta vermelha, visto que o efeito relativo da folha "okra" começa a aumentar quando os efeitos da bráctea frego e da planta vermelha começam a decrescer.

\section{Conclusões}

1. A combinação de mais de uma característica morfológica mutante em uma mesma planta resulta em efeito aditivo para a redução do dano causado pelo bicudo, em teste com chance de escolha.

2. A característica mutante bráctea frego é a mais promissora para redução da população do bicudo, seguida da planta vermelha e por último a folha "okra", 
cujo efeito só se manifesta quando associada à bráctea frego.

3. A característica mutante folha "okra" parece exercer um efeito complementar temporal à bráctea frego e à planta vermelha.

\section{Agradecimentos}

Ao Conselho Nacional de Desenvolvimento Científico e Tecnológico (CNPq), pela concessão de bolsa de estudos.

\section{Referências}

ANDRIES, J.A.; JONES, J.E.; SLOANE, L.W.; MARSHALL, J.G. Effects of okra leaf shape on boll rot, yield, and other important characters of upland cotton, Gossypium hirsutum L. Crop Science, v.9, p.705-710, 1969.

CATELAND, B.; SCHVENDIMAN, J. Etat actuel dês connaissances sur lês caracteres qualitatifs du cottoniere Gossypium hirsutum L. Cotton et Fibres Tropicales, v.31, p.391-407, 1976.

HUNTER, R.C.; LEIGH, T.F.; LINCOLN, C.; WADDLE, B.A.; BARIOLA, L.A. Evaluation of a selected cross-section of cottons for resistance to the boll weevil. Fayetteville: University of Arkansas, 1965. 38p. (Arkansas Agricultural Experiment Station. Bulletin, 700).

JENKINS, J.N.; PARROTT, W.L. Effectiveness of frego bract as a boll weevil resistance character in cotton. Crop Science, v.11, p.739743, 1971 .

JONES, J.E. Effect of morphological characters of cotton on insects and pathogens. In: BELTWIDE COTTON PRODUCTION RESEARCH CONFERENCES, 1972, Memphis. Proceedings. Memphis: National Cotton Council, 1972. p.88-92.

JONES, J.E.; WEAVER, J.B.; SCHUSTER, M.F. Plantas resistentes ao bicudo. In: BARBOSA, S.; LUKEFAHR, M.J.; BRAGA SOBRINHO, R. (Ed.). O bicudo do algodoeiro. Brasília: EMBRAPA-DDT, 1986. p.221-251. (EMBRAPA-DDT. Documentos, 4).

LLEWELLYN, D.J.; BROWN, M.; CONSIUS, Y.; HARTWECK, L.; LAST, D.; MATHEWS, A.; MURRAY, F.; THISTLETON, J. The sciences behind transgenic cotton plants. In: AUSTRALIAN COTTON CONFERENCE, 6., 1992, Broadbeach. Proceedings. Camberra: CRC for Sustainable Cotton Production, 1992. 16p.

MAXWELL, F.G. Plant resistance to cotton insect. Annals of Entomologic Society of America, v.23, p.199-203, 1977.

MITCHEL, H.C.; CROSS, W.H.; McGOVERN, W.L.; DAWSON, E.M. Behavior of boll weevil on frego bract cotton. Journal of Economic Entomology, v.66, p.677-680, 1973.
MONKS, C.D.; PATTERSON, G.; DELANEY, D.P.; PEGUES, M.D. The effects of row width and leaf shape on cotton growth and yield. Auburn: Alabama Agricultural Experiment Station, 1999. 9p. (Alabama Experiment Station Bulletin, 638).

OOSTERHUIS, D.M. Growth and development of a cotton plant. In: CIA, E.; FREIRE, E.C.; SANTOS, W.J. (Ed.). A cultura do algodoeiro. Piracicaba: Potafos, 1999. p.35-55.

PARROTT, W.L; JENKINS, J.N.; SMITH, D.B. Frego bract cotton and normal bract cotton: how morphology affects control of boll weevils by insecticides. Journal of Economic Entomology, v.66, p.222-225, 1973.

SACHS, E.S.; BENEDICT, J.H.; ALTMAN, D.W. Gene pyramiding to improve resistance to insects in cotton expressing the cry/A gene. In: BELTWIDE COTTON PODUCTION RESEARCH CONFERENCES, 1993, New Orleans. Proceedings. Memphis: National Cotton Council, 1993. v.2, p.808-813.

SACHS, E.S.; BENEDICT, J.H.; TAYLOR, J.F.; STELLY, D.M.; DAVIS, S.K.; ALTMAN, D.W. Cry IA(b) insecticidal protein and terpenoides in cotton to resist tobacco budworm (Lepidoptera: Noctuidae). Environmental Entomology, v.25, p.1257-1266, 1996.

SMITH, C.W. Development of cotton with improved fiber quality for Central and Southern Texas. 1997. Disponível em: < h t t p ://ww w c otonic.com/su m mary reports / homepage.cfm?page=932\&ProjectID=80>. Acesso em: 7 ago. 2002.

SOARES, J.J. Aspectos da resistência do bicudo do algodoeiro (Gossypium hirsutum L.) a Anthonomus grandis Boheman, 1843 (Coleoptera: Curculionidae). 1992. 110p. Dissertação (Mestrado) - Universidade Estadual Paulista, Jaboticabal.

SOARES, J.J.; LARA, F.M.; CARVALHO, L.P. de. Da resistência nasce o lucro. Revista Cultivar, n.8, p.16-18, 1999.

THAXTON, P.M.; EL-ZIK, K.M. Comparative characters of recent and prospective Tamcot cultivars releases. In: BELTWIDE COTTON PODUCTION RESEARCH CONFERENCES, 2000, San Antonio. Proceedings. Memphis: National Cotton Council, 2000. v.1, p.521-524.

THAXTON, P.M.; EL-ZIK, K.M. Genetic improvement for yield, and resistance to insects and diseases in Texas cottons 1997. Disponível em: <http://www.cotonic.com/summaryreports/ homepage.cfm?page=931\&ProjectID=142>. Acesso em: 27 set. 1999 .

VASSAYRE, M.; DEGUINE, J.P.; BELLOT, J.L. Os trabalhos do CIRAD relativos à proteção integrada da cultura de algodão no mundo. Paris: CIRAD, [1996?]. 24p.

VIEIRA, R. de M.; LIMA, E.F. Resistência às pragas do algodoeiro. In: BELTRÃO, N.E. de M. (Org.). O agronegócio do algodão no Brasil. Brasília: EMBRAPA Comunicação para Transferência de Tecnologia, 1999. v.1, p.316-360.

WEAVER JUNIOR, J.B.; REDDY, M.S. Boll weevil non-preference, antibiosis and hatchability studies utilizing cotton lines with multiple non-prefered characters. Journal of Economic Entomology, v.70, p.283-285, 1977.

Recebido em 26 de abril de 2004 e aprovado em 21 de setembro de 2004 